\title{
Assessment of knowledge, perception of resident doctors regarding antibiotic resistance and prescription practice at zagazig university hospital, 2013
}

\author{
Maha S. Eltwansy, Ghada M. Salem* \\ Department of community, occupational, environemental medicine medicine, Faculty of Medicine, \\ Zagazig University, Zagazig, Egypt \\ *Corresponding author E-mail: gadamaged@yahoo.com
}

Copyright (-) 2014, Maha S. Eltwansy Md, Ghada M. Salem Md. This is an open access article distributed under the Creative Commons Attribution License, which permits unrestricted use, distribution, and reproduction in any medium, provided the original work is properly cited.

\begin{abstract}
Background: Antibiotics are among the most frequently prescribed drugs worldwide. The overuse and/ or misuse of antibiotics can result in significant consequences as antimicrobial resistance, therapeutic failures, drug toxicities and drug interactions. Since antibiotics are medications that mainly prescribed by physicians, any action aimed at improving use of antimicrobials must necessarily target physicians.

Objectives: To assess knowledge, perception and practice of the resident doctors about antibiotic resistance and antibiotic prescription at Zagazig University Hospital and to identify factors affecting them.

Methodology: A cross-sectional survey was done at Zagazig University teaching hospital between July and September 2013. Self-administrated questionnaire were used to assess resident doctors' knowledge, perception and practice about antibiotics. Results: From 195 target physicians, 175 agreed to participate. The mean score of knowledge about quiz answer, perception about resistance and perception about prescription were (3.6, 3.8, and 3.2 respectively). The age of the resident doctors was statistically significant affecting answering of the eight quizzes and in the perception about antibiotics resistance $(\mathrm{P}=0.00)$ The answering of the eight quizzes, perception about antibiotics resistance and perception about antimicrobial prescription were significantly higher among male doctors than female doctors $(\mathrm{P}=0.000)$. There was also significant association between experience (> 2years) and the answering of the eight quizzes, perception about antibiotics resistance $(\mathrm{P}=0.000)$. Age groups, answering of the eight quizzes, the perception about antibiotics resistance and perception about antimicrobial prescription were statistically significantly affecting practice of resident doctors about antibiotic prescription $(\mathrm{P}<0.05)$.

Conclusion: This study concluded that knowledge of resident doctors and perception about antibiotic prescription was suboptimal. The perception about antibiotic resistance was very high, while doctors' practice in prescribing antibiotic was satisfactory.
\end{abstract}

Keywords: Antibiotic Resistance, Antibiotic Prescription, Resident Doctors, Perception, Knowledge.

\section{Introduction}

The introduction of antimicrobial agents was a breakthrough health intervention that saves millions of lives around the world and that provided a sense of control on the part of clinicians over host-pathogen interactions [1].The overuse and/ or misuse of antibiotics can result in significant consequences as antimicrobial resistance, therapeutic failures, drug toxicities and drug interactions [2]. Antimicrobial resistance has increasingly become a world-wide public health issue. The causes that drive antimicrobial resistance in low income countries are well known. The main factors are irrational drug use such as over-prescription and unnecessary prescription of antibiotics (such as for viral infections), incomplete treatments and self-medication as well as insufficient infection control measures to prevent spread of resistant bacteria both in the community and the hospital [3].Antibiotic resistance is causing not only increased morbidity and mortality but also a high economic burden. Adding a load to health systems in low income countries which are already struggling with chronic underfunding and weak institutional structures [4]. 
Data from the Centers for Disease Control and Prevention's (CDC's) National Nosocomial Infection Surveillance (NNIS) System indicate that not only have the rates of bacterial resistance risen steadily over the past decade but that this resistance is no longer a phenomenon limited to the intensive care unit (ICU) setting. It has been demonstrated that a great deal of antimicrobial use is either unnecessary or inappropriate and that decreasing this use is effective in curtailing resistance. These facts have prompted many to call for improvements in antimicrobial prescribing practices and have led to the creation of position statements and guidelines from national infectious disease (ID) organizations [5].

According to the results of various surveillance studies which were done, the percentage of irrational antibiotics which was reported was $40-60 \%$ [6].

Since antibiotics are medications that mainly prescribed by physicians, any action aimed at improving use of antimicrobials must necessarily target physicians [7]. Knowledge is the first step in modifying behavior in relation to physicians' adherence to clinical practice guidelines and behavior change based on influencing knowledge and attitude is probably most sustainable than indirect manipulation of behavior alone[8].

It is important to understand physician's knowledge about antimicrobial agents, how they acquire and maintain that knowledge, and what factors influence their prescribing of antimicrobials. A better understanding of these underlying factors will permit the development of most effective interventions [9].

\section{The objectives of this study were}

1) To assess knowledge, perception and practice of the resident doctors at Zagazig University Hospital about antibiotic resistance

2) To identify factors affecting knowledge, perception and practice of doctors at Zagazig University Hospital.

\section{Subject and methods}

\subsection{Technical design}

Site: Zagazig University teaching hospital

Subjects: resident doctors prescribing antibiotics in their clinical practice at Zagazig University hospital. The term "resident" referred to doctors after qualification from medical school that were still in their training years for a specialty. Both junior (post-graduate year-1, 2, 3 [PGY-1, 2, 3]) and senior (PGY-4 and PGY-5) residents of the Zagazig University Hospital were targeted. Physicians were identified from departmental records. The physicians were targeted from internal medicine and its specialties as chest, Gastroenterology, Nephrology, Dermatology, general surgery and its specialties as Orthopedic Surgery, gynecology, Pediatric and ENt. Specialties such as laboratory medicine, radiology, psychiatry, ophthalmology, anesthesiology and occupational health were excluded because they prescribe antimicrobial agents less often than do other physicians.

Sample: 205 residential doctors. The sample size was calculated by using computer software Epi-info version 6 assuming that the total number of residential doctors 250, prevalence of knowledge of residential doctors about antibiotic prescription is $15 \%$ (was calculated from pilot study on 20 residential doctors), at $95 \%$ confidence level and $80 \%$ power, the sample will be $171+20 \%$ non-response so sample size 205 doctors, 15 doctors refuse to participate in the study,

10 doctors were leave absence from work and 5 doctors did not complete the questionnaire so response rate was $85.3 \%$. The doctors were chosen randomly according to proportional allocation in each department chosen.

Tools: A self-administered questionnaire was used. Questionnaires were distributed on site during working hours and participants were asked to respond immediately. There was no incentive for physicians to participate and no reminders were supplied. The questionnaire was developed according to a previous questionnaire used in [5] [10] and modified and translate into English.

\subsection{Operational design}

Study design: cross-section study.

Time: This study was carried out from July and September 2013.

Ethical consent

An informed verbal consent was obtained from residential doctors to be enrolled in this study. Written administrative permission from Zagazig hospital manager to perform the study was obtained.

Pilot study: Pilot study was conducted to test the questionnaire. Unclear items were modified to be easily understood by participants.

Data collection: The questionnaire was developed according to a previous questionnaire used in [5] [10] and modified and translate into English. Questionnaire consisted of 30 questions and 8 quizzes. It covered the following topics: 
I) Demographic information included: gender, age, current specialty, physicians' years of training and to whom you describe the antibiotics (either for patients in the outpatients clinics, in the department or in both of them or for the patients in the emergency )

II) knowledge section included:

1) Question to identify the sources of information about antibiotic

2) Series of questions to assess knowledge about factors contributing to antimicrobial resistance which included antibiotic repetition, the treatment not complete, low dose, low quality, transmission present in the hospital and self-medication.

3) Quiz section: it consists of 8 problems solving question, used to assess knowledge of resident doctors about antibiotic prescription in certain medical situation which are most common in the hospital such as 1st quiz was about treatment of choice for 4-year-old child had diarrhea since 4 days ( 3 stools daily), no fever during the past days nor at consultation, the 2 nd one about treatment of choice for 6 -year-old child has fever $\left(38^{\circ} \mathrm{C}\right)$, nasal discharge and a painful throat for two days. At visual inspection, the throat is reddish, 3rd one was about adjust the antibiotic dose for which of one of two patients with impaired renal function. Patient A is a 68 year-old male with cellulitis in the lower limb and administered clindamycin. Patient B is a 64 year-old woman with diabetes who received empirically treatment for sepsis with ceftriaxone, 4th quiz about safe antibiotic was given during the first trimester of pregnancy, $5^{\text {th }}$ one was about antibiotics has the best activity against anaerobes, $6^{\text {th }}$ one was bout antibiotic that Methicillin resistant - Staphylococcus aureus is susceptible to, $7^{\text {th }}$ one was about antibiotic most effectively crosses the blood-brain barrier, $8^{\text {th }}$ one was about the route that make Aminoglycoside antibiotics such as gentamicin are most active when they are administered.

III) Perception section included:

1) Series of questions to assess perception about antimicrobial resistance included: importance of knowing antimicrobial resistance before prescription it. Scope of antimicrobial resistance problem as international problem, national problem or problem in the hospital.

2) Series of questions to assess the perception about prescription of antibiotics included : confident information about antibiotic before prescribe it, overuse of antibiotic in hospital, if the decision to use antibiotics depend on the available drug more than the cause of the infection, Patient demand contribute to overuse in hospital, Patient demand contribute to overused in community, antibiotics available in the hospital are of low quality, the importance of knowing the restricted antibiotic and use the others and prescribe antibiotics for patient doesn't need it, cause no harm for him.

IV) Practice section included: Number of antibiotics prescribed in the last week, review decision to prescribe antibiotics with a senior colleague, if asking a senior colleague, how frequent he/she recommends different antibiotic, difficulty to select the correct antibiotic, During the last year number of receiving some teaching in the department, During the last year, number of receiving training courses and Sources of information about antibiotic prescription.

Scoring of the questionnaire: In the question which asked about whom you describe the antibiotics and in knowledge section $1=$ if the physician chose the choice $0=$ if not chosen and in Quiz part $1=$ if the answer was right $0=$ if the answer was wrong. The perception sections used 5-point Likert response options from "strongly agree" to "strongly disagree", then recoded into positive response (strongly agree, agree, neutral) or negative response (disagree , strongly disagree). Total score of answering quiz questions were 8 (mean score $\geq 3.6 \pm 1.6$ ), the total of questions about perception of antimicrobial resistance were 4 (mean score $\geq 3.8 \pm 1.2$ ), and the total of questions about perception of antimicrobial prescription were 8 (mean score $\geq 3.2 \pm 0.6$ ). Cut of point was used, was mean $<$ mean is considered bad $\% \geq$ mean is considered good.

\subsection{Data management and analysis}

The collected data were entered, analyzed by computer using Statistical Package of Social Sciences SPSS version 10 statistical computer programs. Number and percent were estimated .Chi square test and Logistic regression were used for comparison of qualitative data. The results were considered significant at $\mathrm{p}$ - value $<0.05$.

\section{Results}

Table, 1 shows that the majority of the study sample was male 64\% with mean of age 28.1 (range 26-32years). Most of the respondent doctors belong to internal medicine department $36 \%$ then surgical $33.1 \%$, pediateric $13.1 \%$, Gynecology $12 \%$ and lastly ENT department 5.7\%. More than half of them 56\% had three years of experience in working as resident doctors in his/her department and most of them $71 \%$ prescribed antibiotics for patients in both outpatients' clinics and in the department? 
Table 1: Demographic Data of Resident Doctors at Zagazig University Hospital, 2013.

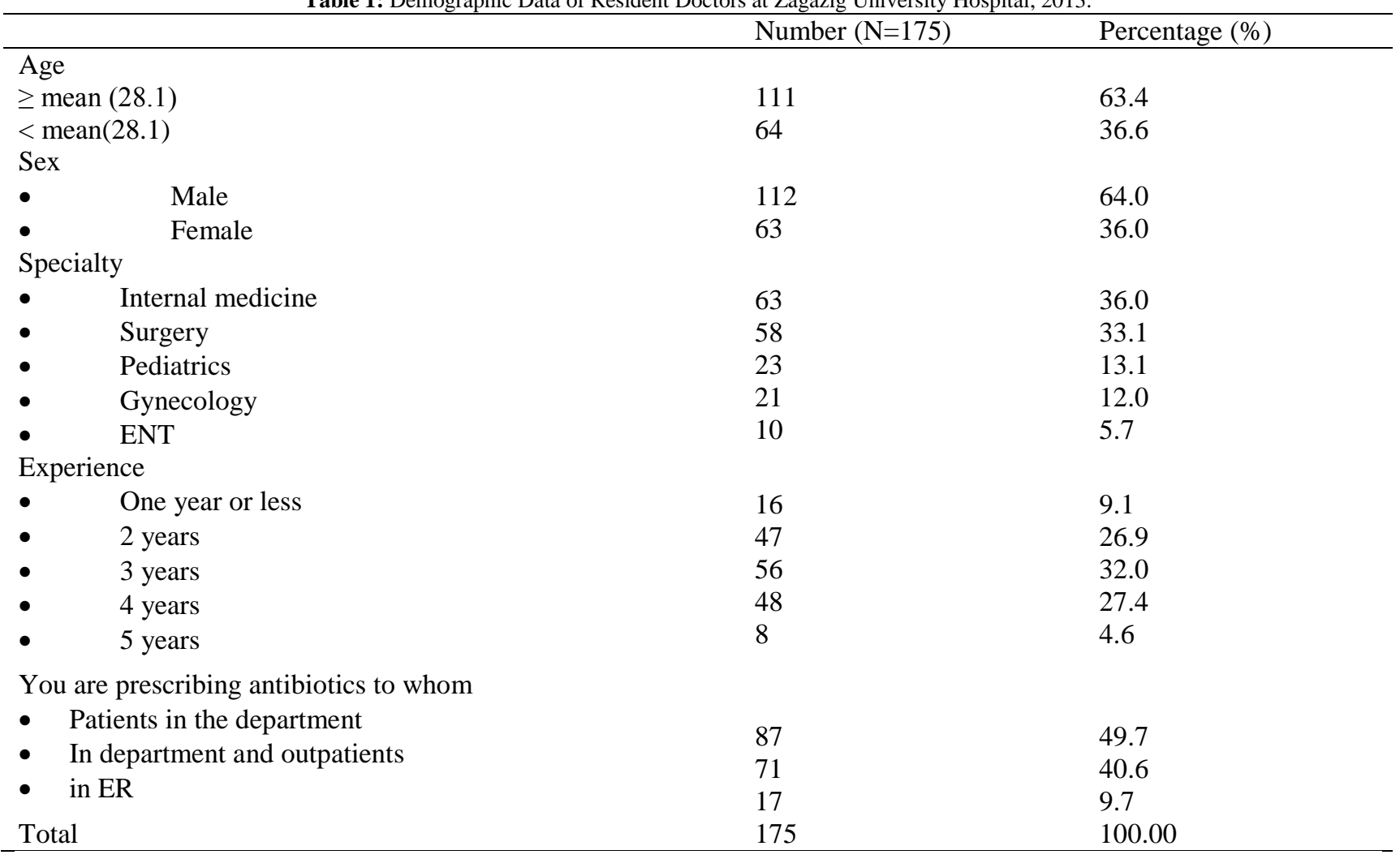

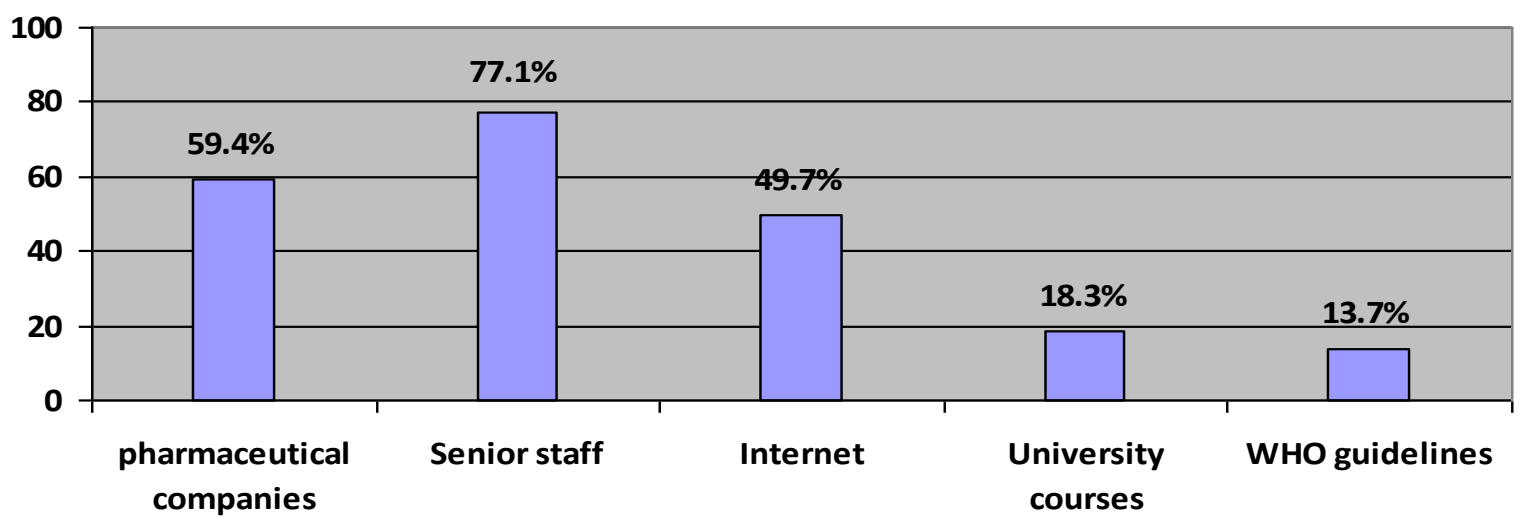

Fig. 1: Sources of Information about Antibiotic of Resident Doctors in Zagazig University Hospital, 2013

Senior staff was the most common source of information about the antibiotics for the resident doctors (77.1\%) followed by the pharmaceutical companies' representatives $(59.4 \%)$, internet $(49.7 \%)$, and university courses $(18.3 \%)$ and the least was the WHO guidelines (13.7\%) (Figure 1).

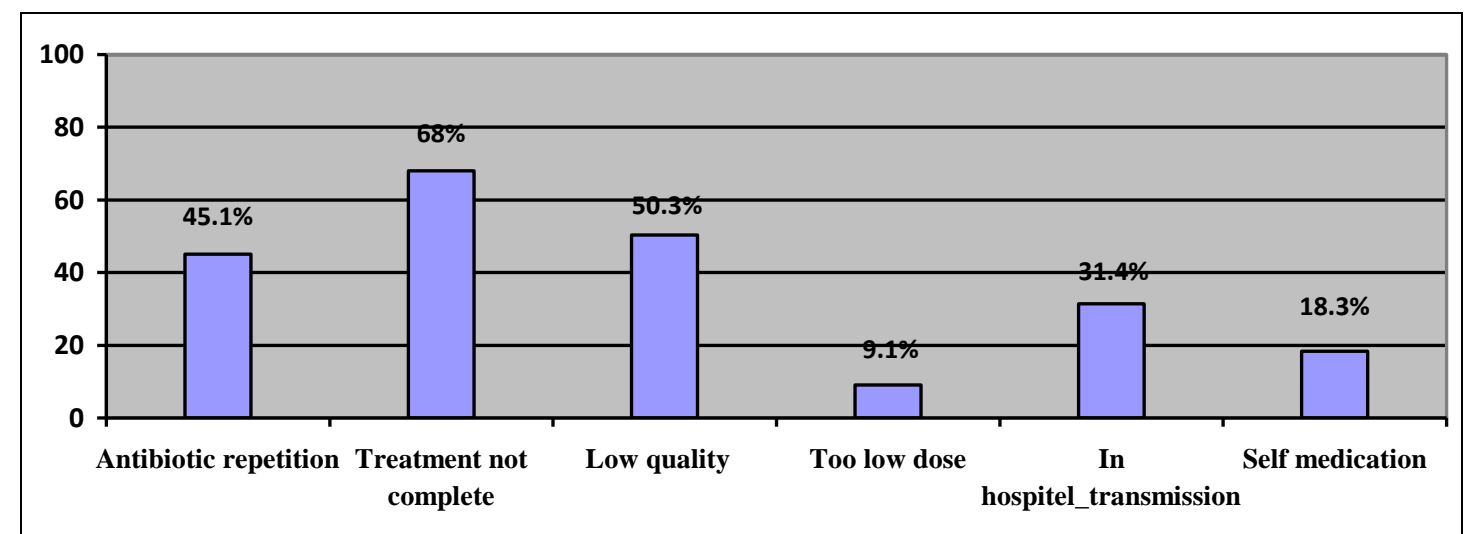

Fig. 2: Knowledge of Resident Doctors about Factors Contributing to Antimicrobial Resistance at Zagazig University Hospital, 2013 
Treatment not complete, low quality of antibiotics and antibiotics repetition $(68 \%, 50.4 \%$ and $45.1 \%$ respectively) were the most common causes known by the doctors to contribute in antimicrobial resistance (figure 2).

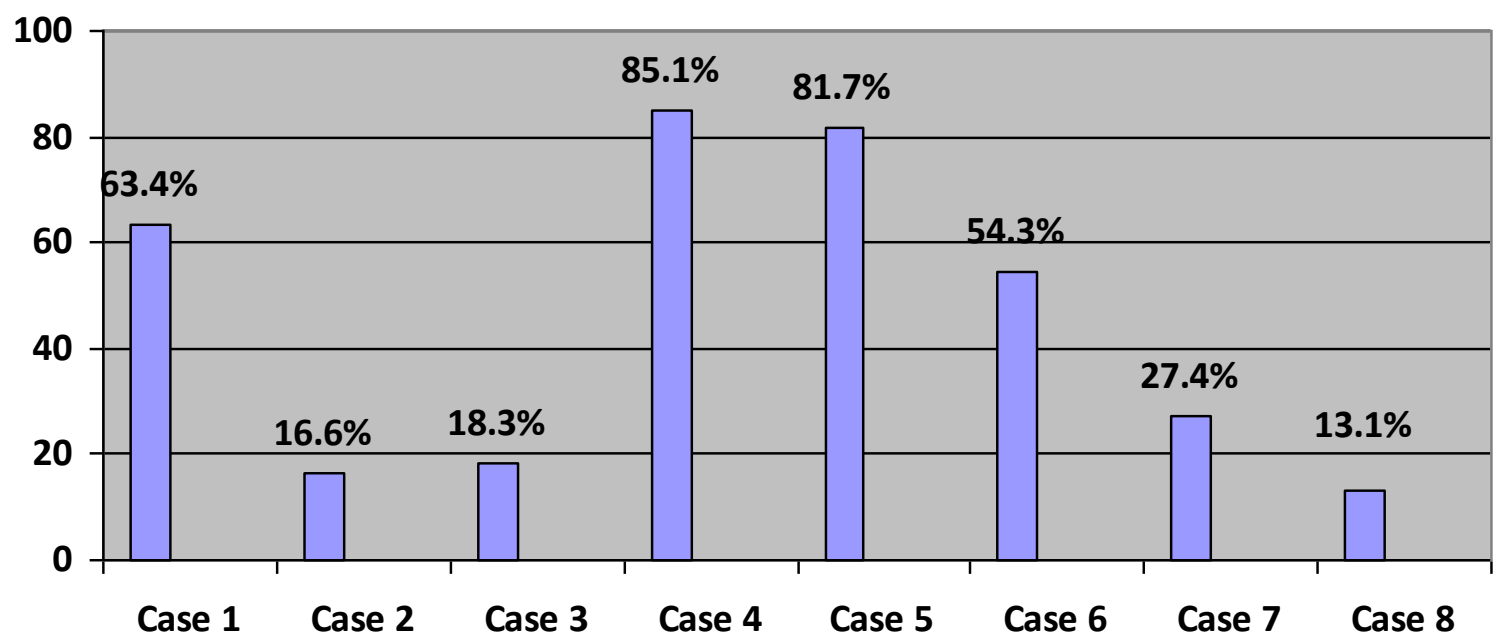

Fig. 3: Knowledge of Resident Doctors about Antibiotic Prescription

The $4^{\text {th }}$ case concerning safe antibiotic during first trimester of pregnency was the most one answered right by the participants $(85.1 \%)$ while the $8^{\text {th }}$ case about route of administration of gentamicine to be most active was the least one answered right $(13.1 \%$ ) (Figure 3$)$.

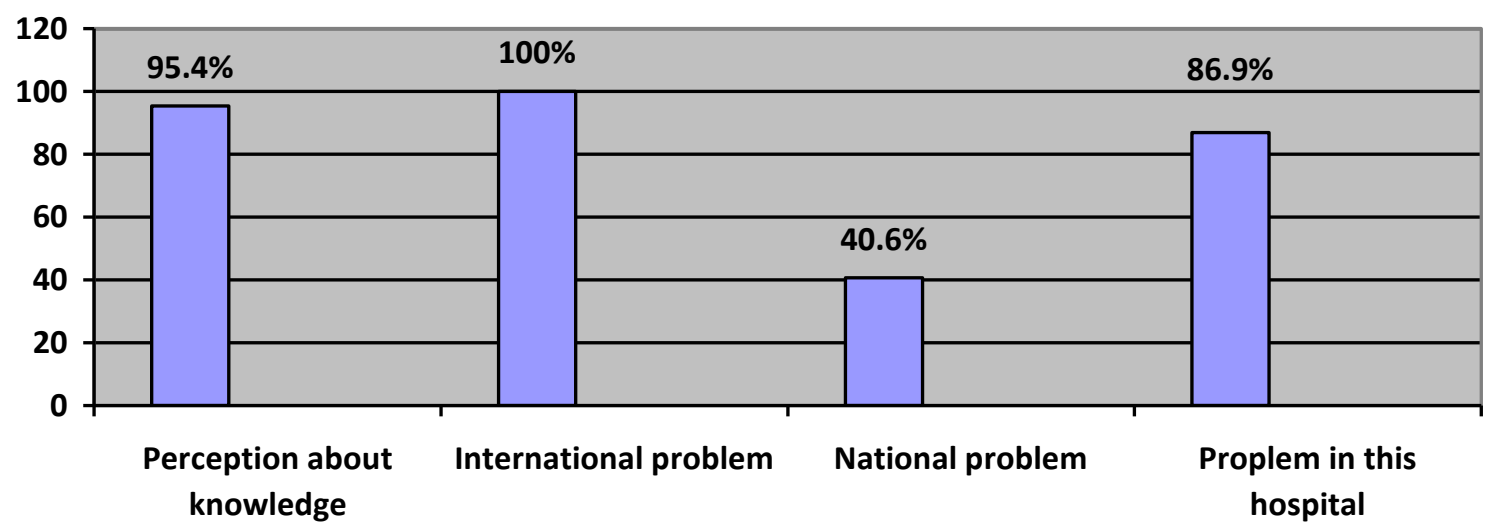

Fig. 4: Positive Response of Resident Doctors on Perception Component of 5-Point Scale about Antimicrobial Resistance

Perception about knowledge about antimicrobial resistance before prescription was positive in nearly all the participant $(95.4 \%)$ and in perception of the scope of the antimicrobial resistance, it was positive in all the participants as consider it an international problem, $86.9 \%$ as problem in the hospital and $40.6 \%$ as national problem (figure 4 )
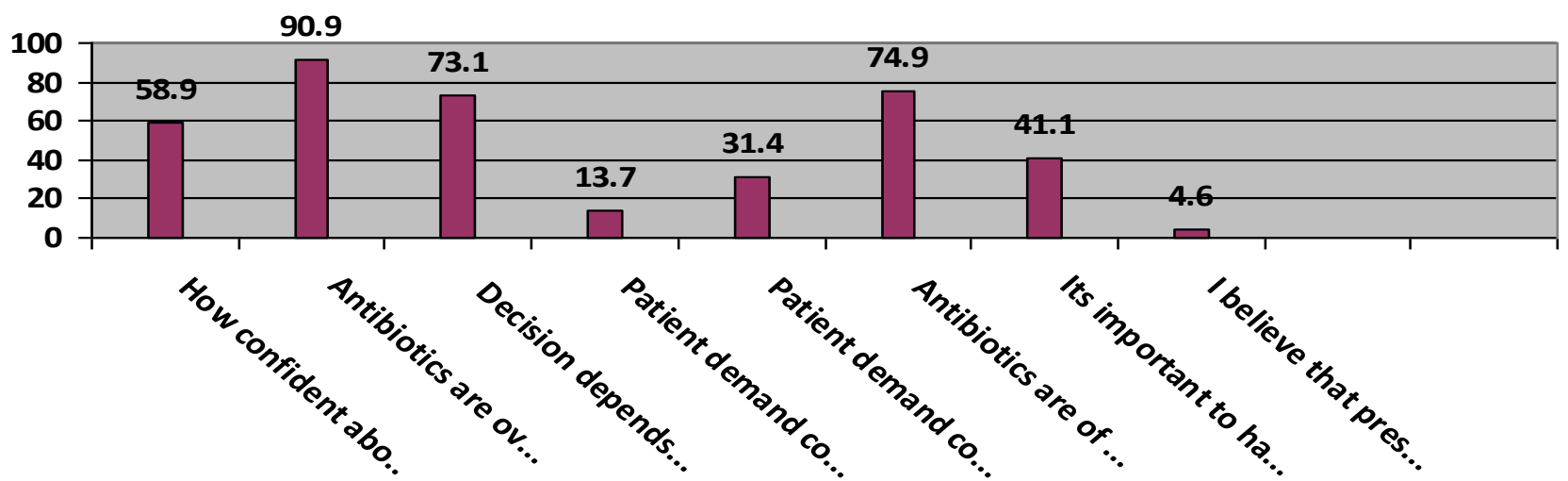

Fig. 5: Positive Response of Resident Doctors on Perception Component of 5-Point Scale about Antibiotic Prescription 
Over using of the antibiotics in the hospital had the highest positive response $(90.9 \%)$ in perception of antibiotic prescription while believing of the physicians that prescribed antibiotics for patient did not need it, would not cause any harm for him had the lowest positive response (4.6\%) (Figure 5).

Table 2: Practice of Resident Doctors about Antibiotic Prescription at Zagazig University Hospital, 2013.

\begin{tabular}{|c|c|c|}
\hline & Number $(\mathrm{N}=175)$ & Percentage $(\%)$ \\
\hline \multicolumn{3}{|c|}{ umber of antibiotics prescribed in the last week } \\
\hline - $\quad \leq 2$ & 18 & 10.3 \\
\hline - $\quad 3-5$ & 110 & 62.9 \\
\hline - $\quad>5$ & 47 & 26.9 \\
\hline \multicolumn{3}{|c|}{ How frequent do you review your decision to prescribe antibiotics with a senior colleague } \\
\hline - $\quad$ Always & 88 & 503 \\
\hline Often & $\begin{array}{l}00 \\
81\end{array}$ & 46.3 \\
\hline Never & $\begin{array}{l}81 \\
6\end{array}$ & 3.4 \\
\hline \multicolumn{3}{|c|}{ If you ask to a senior colleague, how frequent he/she recommends you a different antibiotic } \\
\hline - $\quad$ Always & 32 & 18.3 \\
\hline Often & 143 & 81.7 \\
\hline Never & 0 & 0.0 \\
\hline \multicolumn{3}{|c|}{ It is difficult to select the correct antibiotic } \\
\hline - $\quad$ Yes & 24 & 13.7 \\
\hline No & 151 & 86.3 \\
\hline \multicolumn{3}{|c|}{ During the last year, how many times have you received some teaching in your department } \\
\hline - $\quad 0$ & 103 & 58.9 \\
\hline $1-3$ times & 72 & 41.1 \\
\hline \multicolumn{3}{|c|}{ During the last year, how many times have you received training courses } \\
\hline - $\quad 0$ & 135 & 77.1 \\
\hline $1-3$ times & 40 & 22.9 \\
\hline
\end{tabular}

Most of resident doctors prescribed the antibiotics 3 to 5 times in the last week $(62.9 \%)$ and they reported that they always reviewed their decision with a senior colleague $(50.3 \%)$ who often recommended a different antibiotic (81.7\%) although most of the resident doctors $(86.3 \%)$ did not find any difficult in prescribing antibiotics. Most of the resident doctors didn't receive any teaching in the department or taking any training courses about antibiotics prescription $(58.1 \%, 77.9 \%$ respectively) (Table 2$)$.

Table 3: Association between Knowledge, Perception about Antimicrobial Resistance and Perception about Antibiotic Prescription and Demographic Characteristics of Resident Doctors at Zagazig University Hospital, 2013.

\begin{tabular}{|c|c|c|c|c|}
\hline . & & $\begin{array}{l}\text { Quiz answer } \\
(\mathrm{n}=63) \\
(\text { mean score } \geq 3.6)\end{array}$ & $\begin{array}{l}\text { Perception about resistance } \\
(\mathrm{n}=157) \\
(\text { mean score } \geq 3.8)\end{array}$ & $\begin{array}{l}\text { Perception about prescription } \\
(\mathrm{n}=56) \\
(\text { mean score } \geq 3.2)\end{array}$ \\
\hline \multirow{4}{*}{ Age } & Category & $\mathrm{N}(\%)$ & $\mathrm{N}(\%)$ & $\mathrm{N}(\%)$ \\
\hline & $\leq$ mean $(28.1)$ & $24(38.1)$ & $61(38.9)$ & $24(42.9)$ \\
\hline & $>\operatorname{mean}(28.1)$ & $39(61.9)$ & \multirow{2}{*}{$\begin{array}{l}96(61.1) \\
37.3\left(0.000^{*}\right)\end{array}$} & $32(57.1)$ \\
\hline & $x^{2}(p)$ & $12.7\left(0.00^{*}\right)$ & & $2.2(0.14)$ \\
\hline \multirow{3}{*}{ Gender } & Male & $40(63.5)$ & $106(67.5)$ & $37(66.1)$ \\
\hline & Female & $23(36.5)$ & $51(32.5)$ & $19(33.9)$ \\
\hline & $\mathrm{x}^{2}(\mathrm{p})$ & $14.3\left(0.00^{*}\right)$ & $24.8\left(0.000^{*}\right)$ & $20.5\left(0.000^{*}\right)$ \\
\hline \multirow{6}{*}{ Specialty } & Internal medicine & $25(39.7)$ & $60(38.2)$ & $11(19.6)$ \\
\hline & Surgery & $20(31.7)$ & $55(35.0)$ & $24(42.6)$ \\
\hline & Pediatrics & $10(15.9)$ & $19(12.1)$ & $9(16.1)$ \\
\hline & Gynecology & $5(7.9)$ & $19(12.1)$ & $9(16.1)$ \\
\hline & ENT & $3(4.8)$ & $4(2.5)$ & $3(5.4)$ \\
\hline & $x^{2}(p)$ & $2.5(0.65)$ & $2.23(0.69)$ & $2.19(0.70)$ \\
\hline \multirow{3}{*}{ Experience } & $\leq 2$ years & $24(38.1)$ & $52(33.1)$ & $19(33.9)$ \\
\hline & $>2$ years & $39(61.9)$ & $105(66.9)$ & $37(66.1)$ \\
\hline & $\mathrm{x}^{2}(\mathrm{p})$ & $12.7\left(0.00^{*}\right)$ & $113.7\left(0.000^{*}\right)$ & $0.07(0.79)$ \\
\hline Mean score & Mean $\pm \mathrm{SD}$ & $3.6 \pm 1.6$ & $3.8 \pm 1.2$ & $3.2 \pm 0.6$ \\
\hline
\end{tabular}

Table, 3 demonstrates that the mean score of knowledge about quiz answer, perception about resistance and perception about prescription were $(3.6,3.8$, and 3.2 respectively). It also shows that there was statistically significant difference 
between residents doctors aged more than 28.1 years in answering of the eight quizzes and in the perception about antibiotics resistance $(\mathrm{P} \leq 0.05)$. The answering of the eight quizzes, perception about antibiotics resistance and perception about antimicrobial prescription were significantly higher among male doctors than female doctors. There was also significant association between experience (> 2years) and the answering of the eight quizzes, perception about antibiotics resistance.

Table 4: Multiple Regression Analysis of Factors Affecting Practice of Resident Doctors about Antibiotic Prescription at Zagazig University Hospital, 2013.

\begin{tabular}{lllll}
\hline & $\beta \pm \mathrm{SE}$ & Wald & $\mathrm{P}$ & OR (95\% CI) \\
\hline Age groups & $1.94 \pm 0.52$ & 13.8 & $0.000^{*}$ & $0.1(0.05-0.4)$ \\
Gender & $0.15 \pm 0.4$ & 0.13 & 0.72 & $0.9(0.4-2)$ \\
Experience & $0.75 \pm 0.5$ & 2.28 & 0.13 & $0.5(0.2-1.4)$ \\
Quiz answer & $0.9 \pm 0.4$ & 5.1 & $0.02^{*}$ & $2.5(1.8-10.2)$ \\
Perception about resistance & $3.4 \pm 0.8$ & 17.3 & $0.000^{*}$ & $8.7(5.9-39.3)$ \\
Perception about prescription & $1.4 \pm 0.4$ & 10.5 & $0.001^{*}$ & $4.2(1.8-10.2)$ \\
\hline
\end{tabular}

The result of Logistic regression found that age groups, answering of the eight quizzes, the perception about antibiotics resistance and perception about antimicrobial prescription were statistically significantly affecting practice of resident doctors about antibiotic prescription (Table 4).

\section{Discussion}

This study was done to assess knowledge, perception and practice of resident doctors at Zagazig University Hospital about antibiotic resistance and prescription. A high rate of questionnaire completion $(90 \%)$ was achieved. The reasons for non-responce was unclear, however, non-responders were from varied sociodemographic characters and not belong to specific character, so not expected to bias.

\section{Knowledge}

The results regarding sources of information (fig 1) was consistent with a study Thriemer et al (2013) [11] who found that information from pharmaceutical companies ranked highest in accessibility, while WHO guidelines were used less frequently. About half of the doctors have their information from the internet which can emphasize the use of Elearning in training courses beside the face to face intervention. This was similar to a study among physician in Peru done by Garcia (2011) [12] who reported that internet sources were ranked as the second most useful source, but our result is inconsistent with Garcia (2011) [12] in which advice from colleagues of highest rank (38\% only).

The resident doctors had unsatisfactory knowledge about factors contributing to antimicrobial resistance (fig 2) except for incomplete antibiotic treatment and low quality of antibiotic. This was different than the result of Kheder (2013), Thriemer et al (2013) [7], [11] that found that physicians had a reasonable idea of the major factors contributing to the problem. The results of Wester (2002), Nagvi and Pulcini (2010) [13], [14] show similar results about the cause of antibiotic resistance.

The overall mean score on the knowledge questions answered in the quiz section (fig 3) was very low (3.6/8 points). This result was lower than the results from the similar survey conducted in Peru by Garcia (2011) [12] (6.0/7 points) and another one in Congo by Thriemer (2013) [11] (4.9/8 points). This can be explained by the very low percentage of doctors answering correct answer about three questions in the quiz which are the question about antibiotic prescription for URTI, adjusted dose of antibiotics in renal failure and route of administration of aminoglycoside antibiotic to be active. This result also suggests that antimicrobial education was suboptimal among our resident doctors.

This low level of knowledge about antibiotic resistance and prescription can be explained by high percentage of resident doctors not receiving any teaching or training courses about antibiotics during the last year (table, 2). Also their sources of information were mainly from senior staff and pharmaceutical companies as drug promotions in these settings may not always be content-directed or evidence-based (fig, 1). Doctors aged more than 28 years, males and having experience more than two years seem to have high score (more than 50\%) in the quiz answer (table, 3). So older age and more experience make the doctors improve their knowledge as they have enough time to read and take training courses with the decrease load in work. Also male doctors have better knowledge because they may work more in private and need to increase knowledge.

\section{Perception}

This study demonstrated that resident doctors are very aware of the problem of antimicrobial resistance (mean score 3.8 of a total 4). Their perception both at international and hospital level are very high, while their perception about the problem at the national level is low. This can be attributed to low level of knowledge about the problem in Egypt and its 
rate, while their high perception of the problem in their hospital explained by most the doctors $(90.9 \%)$ believed that antibiotics are over used in their hospital and (74.9\%) believed that antibiotics are of low quality (fig, 5). This result is similar to Srinivasan et al (2004), Navarro et al (2013) [5], [15] but different than Wester et al (2002), Giblin et al (2004) [13], [16] who reported that majority of respondents agreed that antimicrobial resistance was a countrywide problem, but less in their own hospital.

The results of this study concerning perception of the doctors about antibiotic prescription demonstrated that this perception is low (mean score 3.2 of a total 8 ). The perception was high among doctors aged more than 28 years, males, surgery doctors and has experience more than two years but gender was only statistically difference (table, 3 ).

This perception can be affected by many factors as influence of pharmaceutical companies on doctor's perception towards antibiotic prescription as reported in Abdullah et al(2011) [17] especially with 59\% of doctors have their information from pharmaceutical companies. Other social factors such as inadequate resources in health and education systems can direct erratic or suboptimal drug use. For example $73.1 \%$ of doctors make their decision about antibiotic prescription according to available antibiotic rather than cause of infection (fig, 5).

The result of the study conducted in France and Scotland by Pulcini et al (2011) [18] shows similar results regarding confident when prescribing antibiotics. Another study by Carla Morales Guerra et al (2011) [19] was similar to our study who found that a large number of participants believed that physicians prescribe antimicrobials more often than necessary ( $86.7 \%$ of respondents agreed or strongly agreed with this statement), and they perceived the role of inappropriate antimicrobial use as an important cause of the emergence of antimicrobial resistance $(97.7 \%$ of respondents agreed or strongly agreed that this was a cause). On the other hand, this result was inconsistent with Garcia et al(2011) [12] as regard to the need to apply for approval to prescribe restricted antibiotics caused them to seek an alternative antibiotics, poor quality of antibiotics in the hospital and patient demand as thriving factor [12] .

\section{Practice}

Regarding the practice of the doctors about antibiotic prescription it is considered satisfactory as the mean score of practice was $(6.8 \pm 1.3$ not shown in table). This practice is affected by age (more than 28$)$, perception about antibiotic resistance and prescription and quiz answer (table, 4).

Disagreeing the results of the study Garcia et al(2011) [12] which reported that $31 \%$ of their participants agreed that it is difficult for them to select the correct antibiotic, only $6 \%$ always review their decision to prescribe antibiotics with a senior colleague and $74 \%$ reported that senior colleagues sometimes recommended a different antibiotic. This result was inconsistent also with Carla Morales Guerra et al (2011) [19] who found that the majority of participants (84\%) had prescribed two or fewer antibiotics in the last week and $70 \%$ had received some training in antibiotic prescribing in the past 12 months.

The limitation of this study that it is a single-hospital survey and the results may not be representative of the whole region. The doctors were very busy and have no time. This is solved by meeting them late during the day to ensure decrease the flow of patients in the outpatient clinic and their work in the departments. Sometimes the doctors tend to give what they consider to be "correct" answers, rather than their true opinions or practices. This was avoided by assuring complete confidentiality.

\section{Conclusion and recommendation}

This study concluded that knowledge of resident doctors regarding the quiz section and perception about antibiotic prescription was suboptimal. The perception about antibiotic resistance was very high, while doctors' practice in prescribing antibiotic was satisfactory.

Doctors aged more than 28 years, males and with experience more than two years have high score in knowledge about the quiz answer, perception about resistance, while gender only affects the perception about prescription. The practice of doctors is affected by age (more than 28), perception about antibiotic resistance and prescription and quiz answer.

So this study recommends:

1) Intervention fields for improvement of knowledge and perception about antibiotic prescription and these interventions mainly targeted young resident doctors aged less than 28 years, females and with experience less than two years. Health education should direct the issue of no antibiotic prescription for URTI, adjusted dose of antibiotics in renal failure and route of administration of aminoglycoside antibiotic to be active. Also, change perception of doctors as prescribing antibiotics according to patients' demands or available drugs. This intervention better done face to face or through E-learning.

2) The provision of unbiased and evidence based information (as WHO guidelines) about antibiotic and local antibiotic resistance rates to all doctors

3) Increase the teaching and training courses about antibiotics in the departments and encourage the resident doctors to attend

4) Further researches concerning antibiotic resistance and prescription. 


\section{Contributors}

The two researchers designed the study and the questionnaire, determined the objectives and conducted the practical phase; all authors revised the manuscript and have seen and approved the final version.

\section{Acknowledgements}

The authors would like to thank Dr. Ghada El Sharkawy Professor of Public Health and Preventive Medicine, Community and Occupational Medicine Department, Zagazig University, Egypt for her valuable input though revising the tools and the manuscript of this study. Also would like to thank the interviewers and respondents. The authors declare that there are no competing interests. This research paper was financed totally by the authors of the study.

\section{References}

[1] Olivier C, Willimas-Jones B, Doize B, Ozdemir V, "Containing Global Antibiotic Resistance: Ethical Drug Promotion in the Developing World. In: Sosa A, Byarugaba D, Amabile-Cuevas C, Hsueh P, Kariuki S et al.., editors. Antimicrobial resistance in developing countries". First ed. New York: Springer, (2010), pp: 505-524.

[2] Ozkurt Z, Erol S, Kadanali A, Ertek M, Ozden K, Tasyaran MA, "Change in antibiotic use, cost and consumption after an antibiotic restriction policy applied by infectious disease specialist", Journal Infection Disease, Vol.58, (2005), pp:338-43.

[3] Okeke I, "Poverty and root causes of resistance in developing countries. In: Sosa A, Byarugaba D, Amabile-Cuevas C, Hsueh P, Kariuki S et al. ., editors. Antimicrobial resistance in developing countries". First Ed. New York: Springer, (2010), pp:27-36. http://link.springer.com/chapter/10.1007\%2F978-0-387-89370-9_3\#page-1

[4] WHO (2012): The evolving threat of antimicrobial resistance: options for action.

[5] Srinivasan A, Song X, Richards A, Sinkowitz-Cochran R, Cardo D, Rand C, "A Survey of Knowledge, Attitudes, and Beliefs of House Staff Physicians From Various Specialties Concerning Antimicrobial Use and Resistance". Archives Internal Medicine; Vol.164, N.13, (2004), pp:1451-1456. http://archinte.jamanetwork.com/article. aspx?articleid=217189

[6] Tunger O, Karakaya Y, Cetin CB, Dinc G, Borand H, "Rational antibiotic use. Journal Infection Developing Countries"; Vol.3, (2009), pp:8893. http://www.jidc.org/index.php/journal/article/view/19755736

[7] Kheder S I, "Physicians' Knowledge and Perception of Antimicrobial Resistance: A Survey in Khartoum State Hospital Settings". British $\begin{array}{llllll}\text { Journal of Pharmaceutical } & \text { Research; } & \text { Vol.3, } & \text { N.3, } & \text { (2013), } & \text { pp:347-362. }\end{array}$ http://www.sciencedomain.org/abstract.php?iid=211\&id=14\&aid=1159\#.VAoBQsKSwgA

[8] Woolf SH, "Practice guidelines: a new reality in medicine: III. Impact on patient care". Archives Internal Medicine; Vol.153, (1993), pp: 2646-55. http://www.sciencedomain.org/abstract.php?iid=211\&id=14\&aid=1159\#.VAoBosKSwgB

[9] Cabana MDR and CSP owe NR, "Why don't physicians follow clinical practice guidelines?a framework for improvement". JAMA; Vol.282, (1999), pp:1458- 1465.

[10] Jean C L, MarieH N, Carine R, Oscar R P., et al, "Antibiotic use: knowledge and perceptions in two university hospitals". Journal of Antimicrobial Chemotherapy; vol.66, N. 4, (2013), pp:936-940.

[11] Thriemer K, Katuala Y and Jacobs J Antibiotic Prescribing in DR Congo: "A Knowledge, Attitude and Practice Survey among Medical DoctorsandStudents".PLoSOne;Vol.8,N.2,(2013),e55495. http://www.plosone.org/article/info\%3Adoi\%2F10.1371\%2Fjournal.pone.0055495.

[12] Garcia C, Llamocca LP, Garcia K, Jimenez A, Samalvides F, et al.: Knowledge, attitudes and practice survey about antimicrobial resistance and prescribing among physicians in a hospital setting in Lima, Peru. BMC clinical pharmacology 2011, 11: 18.

[13] Wester CW, Durairaj L., Evans AT, Schwartz DN, Husain S and Martinez E, Antibiotic resistance: a survey of physician perceptions. Archives Internal Medicine; Vol.162, (2002), pp:2210- 2216.

[14] Nagvi A and Pulcini C, "Bacterial resistance and antibiotic prescription: a survey of hospital physician perception, attitude, and knowledge". Med Mal Infect Nov; Vol.40, N. 11, (2010), pp:625-31.

[15] Navarro-San Francisco C, Del Toro M.D, Cobo, Javier C \& José H et al., Knowledge and perceptions of junior and senior Spanish resident doctors about antibiotic use and resistance: Results of a multicenter survey. Enfermedades Infecciosas y Microbiología Clínica; Vol.31,(2013), pp:199-204.

[16] Giblin TB, Sinkowitz-Cochran RL, Harris PL, Jacobs S, Liberatore K, et al.:"Clinicians' perceptions of the problem of antimicrobial resistance in health care facilities". Archives of internal medicine. Vol. 164, (2004), pp:1662-1668.

[17] Abdullah M, Zaki, Salah I and Kheder, "Attribute and preference of doctors at primary health care centers in Khartoum State towards antibiotic prescribing". Khartoum Pharmacy Journal; Vol.14, N. 1, (2011), pp:6-10.

[18] Pulcini C, Williams F, Molinari N, Davey P and Nathwani D, "Junior doctors' knowledge and perceptions of antibiotic resistance and prescribing: a survey in France and Scotland". Clinical Microbiological Infection; Vol.17, (2011), pp:80-87

[19] Carla Morales Guerra C M, Pereira C A P, Neto ARN, Cardo D M and Correa L, "Physicians' Perceptions, Beliefs, Attitudes, and Knowledge Concerning Antimicrobial Resistance in a Brazilian Teaching Hospital". Infection Control and Hospital Epidemiology. Vol.28, (2007), p:12. 